\title{
Efeitos da radiofrequência em pacientes com flacidez tissular
}

\author{
Effects of radiofrequency in patients with tissue flaccidity \\ Efectos de la radiofrecuencia en pacientes con flacidez tissular
}

Recebido: 22/10/2021 | Revisado: 29/10/2021 | Aceito: 01/11/2021 | Publicado: 03/11/2021

\author{
Marcilene do Nascimento Mota \\ ORCID: https://orcid.org/0000-0003-1294-321X \\ Centro Universitário da Amazônia, Brasil \\ E-mail: marcilenesamy@gmail.com \\ Ozilene Ferreira de Araújo \\ ORCID: https://orcid.org/0000-0002-0308-0283 \\ Centro Universitário da Amazônia, Brasil \\ E-mail: ozilene.card@gmail.com \\ Naira Patricia Castro de Oliveira \\ ORCID: https://orcid.org/0000-0003-1896-7693 \\ Centro Universitário da Amazônia, Brasil \\ E-mail: nairacastro@outlook.com
}

\begin{abstract}
Resumo
A preocupação e os cuidados com a com a aparência física vem aumentando cada vez mais, dessa forma amplia a procura por técnicas estéticas utilizadas para tratar imperfeições da pele e no corpo. A flacidez é uma "sequela" acarretada por diversos episódios sucedidos ao longo dos anos como a falta de atividade física, o emagrecimento demasiado, o envelhecimento, entre outros. O presente artigo tem como objetivo principal analisar e expor os diversos estudos e pesquisas sobre os efeitos da radiofrequência em pacientes com flacidez tissular. Trata-se de uma revisão narrativa de literatura, com o intuito de permitir que o resumo possa incrementar e alcançar informações relativamente de um delimitado tema em curto espaço de tempo. A pesquisa foi realizada nas principais bases de dados da área da saúde: Scientific Electronic Library Online (SCIELO), PUBMED, LILACS (Literatura Latino-Americana e do Caribe em Ciências da Saúde) e Google Scholar com os seguintes temas: Radiofrequência, Flacidez Tissular e Fisioterapia. A radiofrequência tem se destacado tanto para promover alterações fisiológicas quanto estética. Através da terapia utilizada para este tratamento da flacidez tissular, encontrou firmeza no tecido cutâneo através do efeito decorrente do calor profundo, que é gerado em decorrência da radiofrequência, propagando por meio interno para o meio externo e havendo assim, a degradação do colágeno envelhecido. A partir desta pesquisa observou-se que a Radiofrequência tem resultados positivos no tratamento na sustentação da pele, estimulando as fibras de colágenos e assim reduz a flacidez cutânea.
\end{abstract}

Palavras-chave: Radiofrequência; Flacidez tissular; Fisioterapia.

\begin{abstract}
The concern and care with the physical appearance has been increasing more and more, thus expanding the search for aesthetic techniques used to treat skin and body imperfections. Flaccidity is a "sequel" caused by several episodes that have occurred over the years, such as lack of physical activity, excessive weight loss, aging, among others. The main objective of this article is to analyze and expose the various studies and research on the effects of radiofrequency in patients with tissue flaccidity. It is a narrative literature review, with the aim of allowing the abstract to increase and reach information relatively on a delimited topic in a short period of time. The research was carried out in the main databases in the health area: Scientific Electronic Library Online (SCIELO), PUBMED, LILACS (Latin American and Caribbean Literature in Health Sciences) and Google Scholar with the following themes: Radiofrequency, Tissue Flaccidity and Physiotherapy. Radiofrequency has stood out both to promote physiological and aesthetic changes. Through the therapy used for this treatment of tissue flaccidity, it found firmness in the skin tissue through the effect resulting from the deep heat, which is generated as a result of the radiofrequency, propagating through the internal to the external environment and thus causing the degradation of the aged collagen. From this research, it was observed that Radiofrequency has positive results in the treatment of supporting the skin, stimulating collagen fibers and thus reducing sagging skin.
\end{abstract}

Keywords: Radio frequency; Tissue flaccidity; Physiotherapy.

\section{Resumen}

La preocupación y el cuidado con la apariencia física ha ido aumentando cada vez más, ampliando así la búsqueda de técnicas estéticas utilizadas para tratar las imperfecciones cutáneas y corporales. La flacidez es una "secuela" provocada por varios episodios que se han producido a lo largo de los años, como la falta de actividad física, la pérdida excesiva de peso, el envejecimiento, entre otros. El objetivo principal de este artículo es analizar y exponer los diversos estudios 
e investigaciones sobre los efectos de la radiofrecuencia en pacientes con flacidez tisular. Es una revisión de literatura narrativa, con el objetivo de permitir que el resumen aumente y alcance información relativa sobre un tema delimitado en un corto período de tiempo. La investigación se realizó en las principales bases de datos del área de salud: Scientific Electronic Library Online (SCIELO), PUBMED, LILACS (Literatura Latinoamericana y del Caribe en Ciencias de la Salud) y Google Scholar con los siguientes temas: Radiofrecuencia, Flacidez Tisular y Fisioterapia. La radiofrecuencia se ha destacado tanto por promover cambios fisiológicos como estéticos. A través de la terapia empleada para este tratamiento de la flacidez tisular, se encontró firmeza en el tejido cutáneo a través del efecto resultante del calor profundo, que se genera como consecuencia de la radiofrecuencia, propagándose por el ambiente interno al externo, provocando así la degradación. del colágeno envejecido. A partir de esta investigación, se observó que la Radiofrecuencia tiene resultados positivos en el tratamiento de soporte de la piel, estimulando las fibras de colágeno y reduciendo así la flacidez de la piel.

Palabras clave: Radiofrecuencia; Flacidez tisular; Fisioterapia.

\section{Introdução}

A flacidez é uma "sequela" acarretada por diversos episódios sucedidos ao longo dos anos como a falta de atividade física, o emagrecimento demasiado, o envelhecimento, entre outros. À vista disso, os músculos tornam-se flácidos dado essas circunstâncias. A musculatura perde a tonicidade e sem contornos estabelecidos, as fibras musculares convertem-se atrofiadas e flácidas (Lima \& Rodrigues, 2012).

A flacidez da parede abdominal pode se anunciar em duas formas, a flacidez muscular que é tipificada pela redução do tônus muscular, pelo estiramento do abdômen e a flacidez de pele, acarretada ao estiramento e aniquilação da elasticidade o qual transcorre quando o limite elástico é ultrapassado e o tecido sofre a característica normal, sendo que é muito comum a associação entre as duas formas (Demartini et al., 2015).

A fisioterapia dermatofuncional é ampla e diversa, não somente nos aspetos de prevenção, mais também na reabilitação, possibilitando a recuperação dos Pacientes com inúmeras condições (Melo et al., 2014). A fisioterapia dermatofuncional a cada dia vem ocupando seu espaço e adquirindo mais simpatizantes, os primeiros relatos dos fisioterapeutas trabalhando na área da estética foram em meados dos anos 70, apesar disso, surgiram apenas nos anos 90 as primeiras publicações nacionais de cunho científico (Monteiro et al., 2020). Essa área da saúde ganhou seu espaço no mercado sendo cada dia que passa mais reconhecida pelo cirurgião plástico, pela sociedade e pelo paciente por mostrar tratamentos eficazes nos pós-operatórios estéticos recomendada por grandes cirurgiões (Vieira \& Dayana, 2014).

A radiofrequência tem se destacado tanto para promover alterações fisiológicas quanto estética. Melhora a vasodilatação, o trofismo tissular, a reabsorção do excesso de líquidos intersticiais e o aumento da circulação, obtendo uma melhora na drenagem dos resíduos celulares (Oliveira et al., 2019). Na radiofrequência podemos observar os seus efeitos térmicos, provocando a desnaturação do colágeno causando uma imediata e efetiva contração de suas fibras, ocorrendo a ativação dos fibroblastos ativando a neocolagenização e a reogarnização das fibras colágenas e subsequente remodelamento do tecido (Vargas et al., 2016).

O estudo presente tem como finalidade, descrever os efeitos e benefícios que a Radiofrequência pode provocar no combate a flacidez tissular nos pacientes, reconhecendo quais as estruturas da pele que ocorrem as alterações fisiológicas e estruturais, citando os resultados que a mesma causa nas alterações dermatológicas.

\section{Metodologia}

A revisão da literatura narrativa ou tradicional, apresenta uma temática mais aberta, raramente parte de uma questão minuciosa bem estabelecida, não exigindo um protocolo severo para sua confecção e a busca das fontes não é pré-determinada e nem específica, sendo constantemente menos englobante. A seleção dos artigos é de forma despótica, disponibilizando o autor de informações compelidas a viés de seleção, com maior intervenção da perspicácia passional (Cordeiro et al., 2007). 
O presente estudo trata-se de uma revisão narrativa de literatura sobre os efeitos da Radiofrequência no combate a flacidez da pele. Para a elaboração deste trabalho investigou-se os estudos publicados que apresentam relevância no meio científico sobre o tema proposto.

Foram selecionados como critérios de inclusão: artigos completos disponíveis integralmente nas bases de dados elencados, em idiomas português, espanhol e inglês e relacionados com a relevância do tema. Foram excluídos artigos duplicados, incompletos, resumos, resenhas, debates, artigos publicados em anais de eventos e indisponíveis na íntegra.

A pesquisa foi realizada principalmente em sites eletrônicos tais como o Portal SCIELO (Scientific Eletronic Library Online), PUBMED, LILACS (Literatura Latino-Americana e do Caribe em Ciências da Saúde) e Google Scholar, como também em livros relacionados ao tema em questão: Radiofrequência, Flacidez Tissular e Fisioterapia.

\section{Resultado e Discussão}

A partir das pesquisas realizadas foi possível descrever de forma exploratória acerca do tema escolhido e estabilizar-se alguns principais pontos para serem submetidos e discutidos. As literaturas pesquisadas demonstraram que o uso da Radiofrequência para o tratamento da flacidez, gera alterações nas fibras de colágeno sendo visível através da melhora da tonicidade da pele reduzindo-as.

\section{Sistema Tegumentar e Músculos}

A pele reveste a superfície de aproximadamente $2 \mathrm{~m}$ do corpo, sendo então o maior órgão do corpo humano e a principal barreira física contra o meio externo, desempenhando diversas funções vitais de comunicação e controle que garantem a homeostase do organismo, vivendo em constante transformações ao decorrer dos anos, adquirindo alterações nas suas funções fisiológicas e estruturais (Bernardo et al., 2019).

A epiderme é basicamente, um tecido epitelial estratificado queratinizado, com variações estruturais e funcionais significativas na dependência do seu sítio anatômico. Sua função é produzir queratina fibrosa maleável responsável pela impermeabilidade cutânea. Logo abaixo encontra-se a derme, onde fica a principal massa da pele, sendo um tecido forte, maleável, com propriedades viscoelásticas, e que consiste em um tecido conjuntivo frouxo composto de proteínas fibrosas (colágenos e elastina) embebidas em substâncias basal amorfa (Mendonça \& Rodrigues, 2011). A derme é composta principalmente por fibroblastos que atua na produção de colágeno tipos I e III, na produção de fibras elásticas e também na matriz extracelular (Pinho et al., 2015).

A hipoderme é a última camada, sendo considerada um órgão endócrino, constituídas por adipócitos, contendo as funções de armazenar reserva energética, proteger contra choques, formar uma manta térmica e modelar o corpo (Tassinary et al., 2019).

Abaixo da hipoderme vem a camada muscular onde há grandes variedades nos tipos de fibras, formando um mosaico na anatomia dos músculos esqueléticos. Sendo assim não existe um músculo composto exclusivamente de fibras dos tipos I e II (com seus vários subtipos), isto é, não há somente um único tipo de fibra muscular compondo um determinado músculo, pois os músculos são compostos por diferentes tipos de fibras, mas com a predominância em um tipo específico. Desse modo, os músculos posturais ou tônicos que são responsáveis pela preservação do corpo contra a gravidade, apontam um predomínio de fibras de contração lenta, e os músculos fásicos, responsáveis pela criação de força muscular, são compostos, principalmente, por fibras de contração rápida (Minamoto, 2005).

\section{Flacidez Tissular}

A flacidez tissular refere-se à qualidade ou estado flácido tecidual, ou seja, tecido mole, frouxo e que pode ou não estar associada a uma flacidez muscular. Na flacidez tissular, a pele perde a sua elasticidade, seu tônus e também, o aspecto inestético 
é inevitável. Surge geralmente a partir da terceira década da mulher e em partes bem visíveis do corpo como abdômen, coxas, glúteos, rosto e braços (Cavaleri et al., 2016).

A flacidez tissular, também conhecida como hipotonia da pele é um termo que atribui a qualidade ou estado flácido tecidual. A principal sequela na pele é a perda de elasticidade, procriando um aspecto inestético, associado a redução da funcionalidade do tecido conjuntivo de sustentação, substancialmente das células de fibroblastos (Souza et al., 2021).

A falta de exercícios físicos é considerada como uma das maiores causa da flacidez, pois quando os músculos não são requisitados satisfatoriamente, suas fibras atrofiam-se. O sedentarismo é considerado um dos fatores mais frequentes para seu aparecimento, seguido pela perda de massa muscular e aumento do depósito gorduroso (Lopes \& Brongholi, 2009).

\section{Papel do Fisioterapeuta}

A fisioterapia dermatofuncional auxilia na redução de medidas em pacientes obesos, no pré e pós-operatório, utilizando técnicas e recursos que trazem benefícios à saúde do paciente. $\mathrm{O}$ ato cirúrgico é composto por uma agressão do tecido que mesmo sendo bem encaminhado, pode causar algum tipo de dano na função tecidual, cabendo ao Fisioterapeuta Dermatofuncional atuar com todos os recursos disponíveis para diminuir essas modificações, sendo um forte contribuinte no pré e no pós-operatório (Araújo et al., 2018).

A fisioterapia dermatofuncional é estabelecida em uma base científica sólida, ela é focada na prevenção das complicações pós-cirúrgicas pretendendo restaurar a funcionalidade, tendo um caráter estético e de reabilitação do paciente de forma global, possibilitando a melhora do quadro álgico, a ansiedade, o edema, a funcionalidade do paciente e nas complicações pósoperatórias incluindo o hematoma, infecção, fibroses, seroma, aderências, depressões e motora do nervo facial e fístula salivar, variando de acordo com cada cirurgia e a técnica aplicada (Migotto \& Naudimar, 2013).

\section{Radiofrequência}

A Radiofrequência tem obtido um ressalto como umas das terapias que são mais utilizadas para o tratamento da flacidez cutânea, e, que tem efeito positivo. Esse efeito é decorrente do calor profundo que é gerado pelo aparelho, propagando-se do meio interno para o meio externo, havendo assim, a degradação do colágeno envelhecido e com a elasticidade diminuída, provocando o favorecimento da formação de novas fibras de colágeno que, por sua vez, seria capaz de gerar uma grande elasticidade e firmeza do tecido cutâneo (Silva et al., 2014).

Podendo atuar também no fibroedema geloide, onde têm-se demonstrado a eficácia na redução da pele "casca de laranja"; nos tratamentos pós-lipoaspiração; rugas; cicatrizes; quedas excessivas de cabelo; olheiras; adiposidades; manchas; estrias e fibroses (Duarte \& Mejia, 2013).

A Radiofrequência tem demonstrado grande utilidade na medicina estética devido a indução de efeitos biológicos como: redução da produção de radicais livres, aumento da circulação arterial, a vasodilatação, da drenagem venosa, diminuição de edemas nas áreas com processo inflamatórios referentes ao aumento da temperatura devido a utilização da corrente elétrica de alto frequência controlada, (Vieira, 2016).

A Radiofrequência atuar na pele proporcionando efeitos térmicos, que obtêm como resultado a hiperemia profunda cutânea, onde consequentemente este método vai ocorrer a vasodilatação e subsequente a ativação metabólica celular do local onde está sendo tratado. Os efeitos que provavelmente serão obtidos pela Radiofrequência irão ser demonstrado durante 2 à 6 meses, isso dependerá de paciente para paciente (Monteiro \& Amanda, 2020).

A temperatura atingida permaneceu em torno de 40 a $42^{\circ} \mathrm{C}$, mantendo de 3 a 4 minutos em cada quadrante e utilizando o controlo da temperatura superficial da pele constantemente, usando o termômetro infravermelho Pro-Temp One de marca Molio com $10 \mathrm{~cm}$ de distanciamento da pele (Silva et al., 2018). 
A amostra analisada foi composta por dez artigos científicos que obtiveram os critérios de inclusão da pesquisa, apresentando, assim, relação com a tema do estudo. Os artigos serão apresentados a seguir na Tabela 1, segundo ano de publicação, autores, objetivos, efeitos e conclusão.

Tabela 1 - Apresentação dos artigos segundo ano de publicação, autores, objetivos, efeitos e conclusão. 2021.

\begin{tabular}{|c|c|c|c|}
\hline FONTE & OBJETIVO & EFEITO & CONCLUSÃO \\
\hline Carvalho et al, 2011. & \begin{tabular}{ll}
\multicolumn{2}{l}{ Avaliar a efetividade da } \\
radiofrequência & no \\
tecido colágeno de \\
ratos.
\end{tabular} & $\begin{array}{l}\text { Os efeitos térmicos da radiofrequência } \\
\text { germinam a desnaturação do colágeno } \\
\text { promovendo instantaneamente e } \\
\text { efetiva contração de suas fibras, } \\
\text { ativando fibroblastos ocorrendo a } \\
\text { neocolagenização alterada em } \\
\text { diâmetro, espessura e periodicidade, } \\
\text { afastando a reorganização das fibras } \\
\text { colágenas e subsequente } \\
\text { remodelamento do tecido. }\end{array}$ & $\begin{array}{l}\text { Foi possível concluir em relação } \\
\text { aos efeitos da radiofrequência no } \\
\text { tecido colágeno que três } \\
\text { aplicações utilizando temperatura } \\
\text { de } 37 \text { graus por dois minutos no } \\
\text { dorso de ratos Wistar, derivou na } \\
\text { neocolagênese nas análises que } \\
\text { correspondiam aos sacrifícios em } \\
24 \text { horas e sete dias após a última } \\
\text { aplicação, condizendo com as } \\
\text { afirmações da literatura. }\end{array}$ \\
\hline Tagliolatto, 2015. & $\begin{array}{l}\text { De todas as técnicas de } \\
\text { aquecimento de tecido, } \\
\text { a RF aparenta ser a mais } \\
\text { estabelecida } \\
\text { comprovada } \\
\text { clinicamente, com a } \\
\text { vantagem de chegar até } \\
\text { a profundidade da pele, } \\
\text { visto que até a } \\
\text { hipoderme será capaz de } \\
\text { ser afetada. }\end{array}$ & $\begin{array}{l}\text { O efeito desse aquecimento leva à uma } \\
\text { melhora da microcirculação e ao } \\
\text { subsequente acréscimo do fluxo } \\
\text { sanguíneo ao tecido adiposo, o que } \\
\text { provocará ampliação de seu } \\
\text { metabolismo, homogeneizando a } \\
\text { gordura subdérmica e alargando a } \\
\text { elasticidade da pele. Entretanto, } \\
\text { hipoteticamente, a tecnologia de RF } \\
\text { pode ser utilizada não só na redução da } \\
\text { flacidez, inclusive na diminuição da } \\
\text { circunferência. }\end{array}$ & $\begin{array}{l}\text { Conclui-se que a radiofrequência } \\
\text { para o tratamento estético da pele } \\
\text { é o método em franca evolução } \\
\text { desde sua aparição, há quase duas } \\
\text { décadas. A atuação do uso da RF } \\
\text { mostra ser satisfatória para } \\
\text { pacientes bem nomeados, cuja } \\
\text { flacidez seja leve ou discreta. }\end{array}$ \\
\hline Santos et al, 2016. & $\begin{array}{l}\text { O objetivo desta } \\
\text { pesquisa foi realizar um } \\
\text { levantamento } \\
\text { bibliográfico acerca } \\
\text { aplicabilidade } \\
\text { radiofrequência da } \\
\text { fisioterapia } \\
\text { dermatofuncional. }\end{array}$ & $\begin{array}{l}\text { O efeito da radiofrequência é bem } \\
\text { estudado e externa boa fundamentação } \\
\text { científica. Desse modo, a dermatologia } \\
\text { moderna facultando esse recurso } \\
\text { visando o rejuvenescimento corporal e } \\
\text { facial, bem como quaisquer processos } \\
\text { degenerativos e patologias crônicas } \\
\text { que importunem na diminuição ou } \\
\text { retardo do metabolismo, irrigação e } \\
\text { nutrição tecidual. }\end{array}$ & $\begin{array}{l}\text { Diante dos resultados, foi possível } \\
\text { excogitar que a radiofrequência é } \\
\text { eficaz tanto no tratamento para } \\
\text { rejuvenescimento, rugas e } \\
\text { flacidez, quanto na modulação da } \\
\text { resposta inflamatória e cicatricial, } \\
\text { apresentando melhora do aspecto } \\
\text { estético após interferência. }\end{array}$ \\
\hline Panppen, 2020. & $\begin{array}{l}\text { O objetivo deste estudo } \\
\text { foi distinguir o intervalo } \\
\text { de aplicação da } \\
\text { radiofrequência em } \\
\text { tratamentos de flacidez } \\
\text { e rejuvenescimento } \\
\text { facial logrados em } \\
\text { estudos científicos. }\end{array}$ & $\begin{array}{l}\text { Todos os resultados obtidos } \\
\text { apresentaram uma considerável } \\
\text { melhora na textura e redução da } \\
\text { flacidez e utilizados em diferentes } \\
\text { intervalos de aplicação e com isso não } \\
\text { é possível determinar o tempo } \\
\text { conveniente de aplicação, mas deve-se } \\
\text { avaliar as estruturas que serão } \\
\text { significativa e considerar os eventos } \\
\text { fisiológicos que se desenvolvem a } \\
\text { partir da aplicação. }\end{array}$ & $\begin{array}{l}\text { Os estudos demostram que a } \\
\text { radiofrequência destaca-se por ser } \\
\text { um procedimento não invasivo, } \\
\text { dentre os seus pontos positivos } \\
\text { encontra-se agilidade do } \\
\text { tratamento, na qual as sessões são } \\
\text { rápidas, geram bem estar ao } \\
\text { paciente, não precisando se afastar } \\
\text { de nenhuma diligência para } \\
\text { realizar o tratamento. }\end{array}$ \\
\hline $\begin{array}{l}\text { Duarte \& Mejia, } \\
2013 .\end{array}$ & $\begin{array}{l}\text { Este estudo tem como } \\
\text { objetivo demonstrar os } \\
\text { benefícios da RF no } \\
\text { combate a flacidez, } \\
\text { identificar quais as } \\
\text { estruturas da pele que } \\
\text { ocorrem alterações } \\
\text { fisiológicas com o uso } \\
\text { da RF e esclarecer os } \\
\text { benefícios em curto } \\
\text { prazo que a mesma } \\
\text { causa nas alterações } \\
\text { dermatológicas. }\end{array}$ & $\begin{array}{l}\text { É possível constatar que a RF tem seu } \\
\text { efeito fundamentado no combate a } \\
\text { flacidez, sendo uma técnica segura e } \\
\text { bem tolerável tanto para o profissional } \\
\text { quanto ao cliente que se submete a } \\
\text { técnica. A realização de mais pesquisas } \\
\text { é imprescindível para contribuir com o } \\
\text { crescimento do conhecimento acerca } \\
\text { do uso da Radiofrequência no combate } \\
\text { a flacidez. }\end{array}$ & $\begin{array}{l}\text { Com o passar do tempo, a } \\
\text { produção de colágeno e elastina } \\
\text { vai sendo diminuídas, conduzindo } \\
\text { a desestruturação das fibras } \\
\text { elásticas e colágenas, e tendo } \\
\text { como resultado uma pele sem } \\
\text { firmeza e elasticidade. A } \\
\text { Radiofrequência com a } \\
\text { temperatura elevada }\left(40^{\circ} \mathrm{C}\right) \text {, } \\
\text { durante a aplicação aumenta a } \\
\text { consistência do colágeno, } \\
\text { conseguindo assim aperfeiçoar a } \\
\text { flacidez da pele. }\end{array}$ \\
\hline Vargas et al, 2016. & $\begin{array}{l}\text { O objetivo deste } \\
\text { trabalho é demonstrar a } \\
\text { importância do } \\
\text { tratamento de } \\
\text { radiofrequência e como } \\
\text { os resultados são } \\
\text { satisfatórios, } \\
\text { demonstrando a eficácia } \\
\text { nos tratamentos } \\
\text { estéticos relacionados a } \\
\text { rugas e flacidez de pele. }\end{array}$ & $\begin{array}{l}\text { No momento que o organismo constata } \\
\text { um aumento na temperatura que o } \\
\text { fisiológico, aumenta a vasodilatação } \\
\text { com abertura dos capilares, o que } \\
\text { melhora o trofismo tissular, a } \\
\text { reabsorção dos líquidos intercelulares } \\
\text { excessivos e a ampliação da circulação. } \\
\text { Com isso, ocorre um ganho nutricional } \\
\text { de oxigênio, nutrientes e } \\
\text { oligoelementos, melhorando o sistema } \\
\text { de drenagem dos resíduos celulares. }\end{array}$ & $\begin{array}{l}\text { A partir desta pesquisa observou- } \\
\text { se que a Radiofrequência tem } \\
\text { resultados positivos para a } \\
\text { flacidez, encoraja as fibras de } \\
\text { colágenos e assim reduz as rugas e } \\
\text { flacidez cutânea. O tratamento por } \\
\text { radiofrequência tem se } \\
\text { evidenciado muito benéfico e } \\
\text { eficaz em relação às correções dos } \\
\text { sinais do envelhecimento e } \\
\text { flacidez da pele. }\end{array}$ \\
\hline
\end{tabular}




\begin{tabular}{|c|c|c|c|}
\hline Lofeu, 2015. & $\begin{array}{l}\text { O principal objetivo } \\
\text { deste estudo é retificar a } \\
\text { literatura sobre a técnica } \\
\text { de radiofrequência } \\
\text { aplicada na gordura } \\
\text { localizada no abdômen. }\end{array}$ & $\begin{array}{l}\text { A Radiofrequência é uma técnica } \\
\text { utilizada substancialmente para o } \\
\text { estimulo e produção do colágeno, mas } \\
\text { também gera uma energia que faz com } \\
\text { que o aparelho alcance as camadas de } \\
\text { gordura, reduzindo assim o volume das } \\
\text { células gordurosas e agilizando o seu } \\
\text { metabolismo, tornando-se um } \\
\text { tratamento estético moderno e } \\
\text { completo na perda de medidas } \\
\text { abdominais }\end{array}$ & 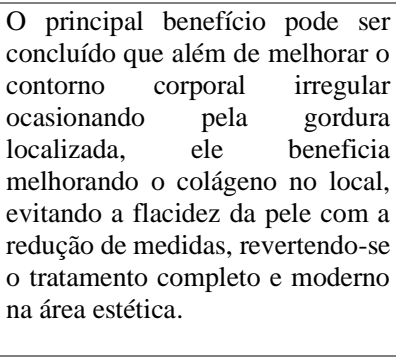 \\
\hline $\begin{array}{l}\text { Araújo \& Moreira, } \\
\text { 2015. }\end{array}$ & $\begin{array}{lr}\text { O objetivo é } & \text { induzir } \\
\text { algum dano } & \text { térmico } \\
\text { para, } & \text { assim, } \\
\text { incentivando } & \text { a } \\
\text { neocolagênese } & \text { em } \\
\text { camadas profundas da } \\
\text { pele e } & \text { tecido } \\
\text { subcutâneo. No entanto, } \\
\text { muitos } & \text { desses } \\
\text { dispositivos não foram } \\
\text { testados e reus } \\
\text { parâmetros ainda não } \\
\text { são aceitos pela } \\
\text { comunidade científica. }\end{array}$ & $\begin{array}{l}\text { Os resultados mostraram que o } \\
\text { principal efeito fisiológico é estimular } \\
\text { a síntese de colágeno. Não houve } \\
\text { homogeneidade entre os estudos em } \\
\text { relação à maioria dos parâmetros } \\
\text { usufuídos e a qualidade metodológica } \\
\text { dos estudos e o nível de evidência para } \\
\text { o uso da radiofrequência são baixos. } \\
\text { Isso impossibilita a determinação de } \\
\text { parâmetros eficazes para o uso clínico } \\
\text { desse dispositivo no tratamento da } \\
\text { flacidez da pele. }\end{array}$ & $\begin{array}{l}\text { O uso de RF tem se baseado mais } \\
\text { no marketing do que por razões } \\
\text { técnico-científicas, visto que } \\
\text { existe um aumento nos números de } \\
\text { aparelhos disponíveis no mercado } \\
\text { e essa quanridade aumenta a cada } \\
\text { dia, sem estudos com bons níveis } \\
\text { de evidência sendo } \\
\text { realizados. Estudos experimentais } \\
\text { são necessários para fazer uma } \\
\text { correlação precisa entre a } \\
\text { temperatura da epiderme e da } \\
\text { derme, a fim de esclarecer mais } \\
\text { ainda a eficácia da RF no } \\
\text { tratamento da flacidez da pele, } \\
\text { principalmente com equipamentos } \\
\text { brasileiros. }\end{array}$ \\
\hline $\begin{array}{l}\text { Santos \& Letícia, } \\
2017 .\end{array}$ & $\begin{array}{l}\text { Avaliar se o tratamento } \\
\text { de radiofrequência pode } \\
\text { ser utilizado em pós- } \\
\text { operatório de cirurgia } \\
\text { bariátrica, rom } \\
\text { propósito de recuperar a } \\
\text { tonicidade da pele } \\
\text { abdominal, isentando os } \\
\text { indivíduos de realizar a } \\
\text { cirurgia reparadora. }\end{array}$ & $\begin{array}{l}\text { Somente o tratamento com } \\
\text { radiofrequência na flacidez ocasionada } \\
\text { pela perda de peso em indivíduos que } \\
\text { tenham realizado a cirurgia bariátrica, } \\
\text { não germinaria o efeito necessário para } \\
\text { que não fosse realizada uma cirurgia } \\
\text { reparadora, porém, a radiofrequência, } \\
\text { após a cirurgia reparadora, seria ideal } \\
\text { para revitalizar e restaurar a pele, sendo } \\
\text { que, ainda não recuperou totalmente ou } \\
\text { quase que globalmente o seu tônus. }\end{array}$ & $\begin{array}{l}\text { Com base nos estudos avaliados e } \\
\text { apresentados, foi possível concluir } \\
\text { que primeiramente, para que o } \\
\text { tratamento de radiofrequência } \\
\text { tenha um resultado eficaz, é } \\
\text { inevitável que seja realizado no } \\
\text { mínimo } 8 \text { sessões, sendo que em } \\
\text { cada sessão, ao atingir a } \\
\text { temperatura de } 41^{\circ} \mathrm{C} \text {, a manopla } \\
\text { permaneça em torno de } 5 \text { minutos } \\
\text { na área tratada, o intervalo entre } \\
\text { cada sessão deve ser de } 7 \text { dias, já } \\
\text { que a retração das fibras colágenas } \\
\text { subsiste em média } 15 \text { dias, } \\
\text { realizando a manutenção uma vez } \\
\text { ao mês após o fim do tratamento. }\end{array}$ \\
\hline $\begin{array}{l}\text { Gonçalves \& Scur, } \\
2012 .\end{array}$ & $\begin{array}{l}\text { O objetivo deste estudo } \\
\text { foi avaliar os efeitos da } \\
\text { radiofrequ } \\
\text { ência bipolar no aspecto } \\
\text { de flacidez da pele, após } \\
\text { processo gestacional, } \\
\text { com aplicabilidade de } \\
\text { radiofrequência bipolar } \\
\text { da marca CECBRA em } \\
\text { região abdominal e } \\
\text { flancos. }\end{array}$ & $\begin{array}{l}\text { Os resultados observados foram a } \\
\text { redução dos valores de perimetria e } \\
\text { diminuição e flacidez na comparação } \\
\text { de imagens. Após o fim das } \\
\text { intervenções, considera-se que houve } \\
\text { crescimento no aspecto de flacidez } \\
\text { abdominal com redução das medidas } \\
\text { perimétricas de cicatriz umbilical e de } \\
10 \mathrm{~cm} \text { abaixo e acima da cicatriz } \\
\text { umbilical. }\end{array}$ & $\begin{array}{l}\text { Neste estudo foi notado que a } \\
\text { utilização da radiofrequência } \\
\text { bipolar } \\
\text { CECBRA produziu melhora na } \\
\text { flacidez tissular abdominal. } \\
\text { Comprovando a eficácia do } \\
\text { tratamento com a radiofrequência } \\
\text { bipolar CECBRA para diminuição } \\
\text { da flacidez cutânea na região } \\
\text { abdominal. }\end{array}$ \\
\hline
\end{tabular}

Fonte: Mota, Araújo e Oliveira (2021).

Observando os artigos estudados, pode-se observar que os mesmos tratam-se de pesquisas bibliográficas que demonstram a radiofrequência como um procedimento não invasivo. Um dos principais benefícios do tratamento, é que os pacientes não precisam se afastar do seu trabalho para realizar tal procedimento.

É uma técnica utilizada principalmente para causar estimulo e a produção do colágeno, como também gerar uma energia que faz com que o aparelho alcance as camadas de gordura, com isso, reduzindo o volume das células gordurosas. $\mathrm{O}$ efeito do aquecimento leva à melhora da microcirculação e ao consequente acréscimo do fluxo sanguíneo ao tecido adiposo, o que provocará aumento de seu metabolismo. 
As intervenções fisioterapêuticas em dermatofuncional, tem conquistado o seu espaço através dos recursos oferecidos para dar aos pacientes uma melhor qualidade de vida e sensação de bem estar físico e emocional, tratando das disfunções estéticas do corpo humano. É uma especialidade da fisioterapia que atua na prevenção, promoção e recuperação do sistema tegumentar.

\section{Conclusão}

A flacidez é um problema cada vez mais frequente em pacientes que passaram por algum processo de emagrecimento e a fisioterapia dermatofuncional tem demostrado em evidencia no mercado, trazendo tecnologias inovadoras, com resultados positivos proporcionando o aperfeiçoamento na autoestima de quem se sujeita a técnica. Os estudos demostram que a radiofrequência se destaca por ser um procedimento não invasivo, através dos seus pontos positivos encontra-se facilidade do tratamento, na qual as sessões são rápidas, procriando bem estar ao paciente, sendo assim, não precisam se afastar de nenhuma atividade para a realização do tratamento.

A Radiofrequência com a temperatura atingindo $\left(41^{\circ} \mathrm{C}\right)$, com a manopla permanecendo em torno de 5 minutos em cada área tratada durante a aplicação, aumenta a densidade do colágeno, conseguindo assim melhorar a flacidez da pele. O principal benefício pode ser concluído que além de produzir o contorno corporal irregular causado pela gordura localizada, ele favorece melhorando o colágeno no local, esquivando-se a flacidez da pele com a redução de medidas e tornando o tratamento completo e moderno na área estética.

A partir desta pesquisa observou-se que a Radiofrequência tem resultados positivos no tratamento na sustentação da pele, estimulando as fibras de colágenos e assim reduz a flacidez cutânea. Com este artigo, foi possível constatar que a Radiofrequência tem seu efeito comprovado no combate a flacidez tissular e é uma técnica segura e bem tolerável, tanto para o profissional quanto ao cliente que se submete a técnica.

A realização de mais pesquisas é imprescindível para cooperar com o crescimento do conhecimento, quanto ao uso da Radiofrequência no combate a flacidez e o seu efeito, o que virá conduzir os profissionais no uso desta técnica e alcançando os resultados cabíveis.

\section{Referências}

Araújo, A. R., Soares, V. P. C., Silva, F. S. \& Moreira, T. S. (2015). Radiofrequência no tratamento da flacidez cutânea: mito ou verdade. Revisão •Um. Bras. Dermatol. 90 (5).

Araújo, C. A. B., Queiroz, L. F. H., Cavalcante, A. S. \& Pontes, R. B. (2018). Efeitos dos recursos da fisioterapia dermatofuncional sobre a perda de peso e sobre os marcadores de risco cardiovascular em paciente obesos. Revista brasileira de fisiologia do exercício; 17(3): 156-64.

Bernardo, A. F. C. (2019). Pele: alterações anatômicas e fisiológicas do nascimento a maturidade. Revista Saúde em foco (11).

Carvalho, G. F. et al. (2011). Avaliação dos efeitos da radiofrequência no tecido conjuntivo. Moreira Jr Editora | RBM Revista Brasileira de Medicina.

Cavaleri, T. Silva, J. S., Dias, C., Almeida, A. A., Pereira, V. K. \& Buava, R. C. (2016). "benefícios da radiofrequência na estética”. revistaonline@ unifia.edu.br, Página 215.

Cordeiro, A. M., Oliveira, G. M., Rentería, J. M. \& Guimarães, C. A. (2007). Revisão sistemática: uma revisão narrativa. Comunicação Científica • Rev. Col. Bras. Cir. 34 (6) • Dez.

Demartini, E. et al. (2015). Atuação da Fisioterapia Dermatofuncional na Flacidez Cutânea e Muscular Abdominal em Mulheres no Puerpério: Revisão da Literatura. Rev Bras Terap e Saúde, 6(1):13-19.

Duarte, A. B. \& Mejia, D. P. M. (2013). A utilização da radiofrequência como técnica de tratamento da flacidez corporal. https://portalbiocursos.com.br/ohs/data/docs/19/35,

Gonçalves, V. P. \& Scur, N. (2012). Estudo de Caso: Uso da radiofrequência bipolar em flacidez tissular abdominal. https://docplayer.com.br/30698528

Lofeu, G. M. (2015). Atuação da radiofrequência na gordura localizada no abdômen: revisão de literatura, Revista da Universidade Vale do Rio Verde, Três Corações, 13(1), 571-581.

Lopes, S.C. \& Brongholi, K. (2009). A utilização da corrente russa no tratamento da flacidez muscular abdominal. http://fisiotb.unisul.br/Tccs/04a/cristiana/artigocristinasouza.pdf. 
Lima, E. P. F. \& Rodrigues, G. B. O. (2012). A estimulação russa no fortalecimento da musculatura abdominal. ABCD Arq Bras Cir Dig;25(2):125-128.

Melo, P. I. S. P. C. (2014). Atuação Do Fisioterapeuta Dermatofuncional e seu Reconhecimento Pelos Profissionais De Saúde Na Região De Lisboa. Lisboa. http://hdl.handle.net/10400.21/4811.

Mendonça, R. S. C. \& Rodrigues, B. L. G. (2011). As principais aletrações dermatológicas em pacientes obesos, ABCD Arq Bras Cir Dig, $24(1)$ : 6873.

Migotto, J. S. \& Naudimar, D. P. S. (2013). Atuação fisioterapeutica dermatofuncional no pós operatório de cirurgias bariátrica. Revista Eletrônica de Gestão \& saúde.

Minamoto, V. B. (2005). Classificação e adaptações das fibras musculares: Uma Revisão. Fisioterapia e Pesquisa; 12 (3):50-5.

Monteiro, E. M. O. \& Amanda, V. N. S. S., (2020). A eficácia da radiofrequência no tratamento de rugas e flacidez facial em mulheres após os 50 anos. Revista Liberum accessum 6(1): $39-49$.

Monteiro, R. S., Bezerra, K. M., Lima, T. C. \& Braga, S. A. S. (2020). Perfil dos usuários atendidos pela fisioterapia dermatofuncional em uma clínica escola de Belém, Pará. Rev. Pesqui. Fisioter. Salvador, 10(2):232-239.

Oliveira, K. C. C., Macuch, R. S., Silva, E. S. \& Bennemann, R. M. (2019). Rádiofrequencia para redução do risco cardiovascular e melhora da autoestima em mulheres na meia idade. Revista Enfermagem Atual in Derme - 88-26.

Panppen, S. (2020). Intervalo de aplicação entre as sessões de radiofrequência: revisão de literatura. Santa Cruz do Sul. http://hdl.handle.net/11624/294. Acesso em $22 / 10 / 2021$

Pinho, A. M. S., Pereira, I. S. O., Odo, M. E. Y. \& Eça, L. P. M. (2015). Estudo histológico comparativo e controlado de fibras colágenas da pele humana após terapia celuar com fibroblastos, Surg Cosmet Dermatol, 7 (3): 206-10.

Santos, A. R. G. \& Leticia, C. F. L. (2017). Aplicabilidade da radiofrequência na hipotonia cutânea pós cirurgia bariátrica, Rio de Janeiro. Trabalho de Conclusão de Curso (Graduação) - Centro Universitário Hermínio Da Silveira - Ibmr Laureate International Universities Curso Bacharelado Em Estética. Rio de Janeiro RJ.

Santos, A. O., Santos, L. N., Pereira, L. G. S., Trindade, M. A. F., Santos, S. N. L. \& Santana, L. S. (2016). Aplicação da Radiofrequência em Fisioterapia Dermatofuncional, Universidade Tiradentes/Fisioterapia/Aracaju, SE.

Silva, A. L. S. M. et al. (2014). Os efeitos do kinesio taping e da radiofrequência na flacidez cutânea glútea. Revista Científica da Escola da Saúde. Universidade Potiguar, 3(2).

Silva, P. R., Andrade, A. G. F. \& Facchinetti, J. B. (2018). Radiofrequência no tratamento de rugas: uma revisão integrativa. Id on Live Ver. Mult. Psic. 11(39).

Souza, M. O. M., Nascimento, A. K. C., Santos, A. S., Soares, I. J. P. \& Silva, R. M. V. (2021). Efeitos do microagulhamento associado a radiofrequência no tratamento de flacidez abdominal em mulheres: Estudo experimental. Fisioterapia Brasil;22(4):597-608.

Tagliolatto, S. (2015). Radiofrequência: método não invasivo para tratamento da flacidez cutânea e contorno corporal. Surgical \& Cosmetic Dermatology, 7(4).

Tassinary, J. (2019). Raciocínio clínico aplicado a estética facial. Ed. Estética Experts. 32-42p.

Vargas, A. P. C. et al. (2016). Benefícios da radiofrequência no envelhecimento e flacidez da pele. https://home.unicruz.edu.br/seminario/anais/anais-2016.

Vieira, G. S. K. (2016). Importância da radiofrequência em tratamentos estéticos: revisão da literatura. Pontifícia Universidade Católica de Goiás - Departamento de Fisioterapia, Goiânia - GO.

Vieira, L. M. \& Dayana, P. M. M. (2014). Fisioterapia dermatofuncional utilizando o recurso da drenagem linfática manual em pacientes pós cirurgia bariátrica. https://portalbiocursos.com.br/ohs/data/docs/18/84. 